\title{
Relações Interpessoais no Contexto do Projeto Sérgio Arouca: Contribuições para Formação Médica
}

\section{Interpersonal Relations within the Context of the Sérgio Arouca Project: Contributions to Medical Training}

\author{
Júlia de Sá Liston ${ }^{I}$ \\ Mariana Andréa de Moura Henicka \\ Rita de Cássia Gabrielli Souza Lima ${ }^{1 \bullet}$
}

\section{PALAVRAS-CHAVE}

- Relações Interpessoais.

- Relações ComunidadeInstituição.

- Educação Médica.

- Atenção Primária à Saúde.

- Sistema Único de Saúde.
O Sistema Único de Saúde é um patrimônio nacional conquistado na VIII Conferência Nacional de Saúde e reconhecido pela Constituição Federal de 1988. A mesma Constituição que o aprovou exigiu um horizonte democrático para a formação em saúde no Brasil, a ser explorado por ensino, pesquisa e extensão. O horizonte requerido fez-se possível (e está constitucionalmente vivo) graças ao art. 207 da Constituição Federal, que determina às universidades o cumprimento do princípio da indissociabilidade entre as três modalidades formativas. Este artigo analisa características éticas, políticas e epistemológicas das relações interpessoais experimentadas na vivência do Projeto Sérgio Arouca, na perspectiva de acadêmicos do curso de Medicina da Universidade do Vale do Itajaí (SC), Brasil. O Projeto Sérgio Arouca, criado em 2009 e inspirado no Projeto Rondon, tem características extensionistas, que possibilitam aos estudantes de Medicina imersão no contexto social da atenção básica de territórios catarinenses socialmente desfavorecidos. Esta pesquisa configura-se como um estudo social de natureza qualitativa, de nível exploratório e caráter analítico. Unindo ensino, extensão e pesquisa, foi desenvolvida com sete acadêmicos por meio da técnica de grupo focal e diário de campo. Os resultados evidenciaram que as relações interpessoais desenvolvidas no contexto do projeto foram atravessadas por uma ética aplicada, por uma epistemologia dialética e por uma ação política responsiva consigo e com o outro. Desta forma, o projeto foi teorizado como uma trégua ao revelar a potencialidade de desacelerar tempos e valorizar a formação fora da estrutura epistêmica curricular do dia a dia, possibilitando encontros reflexivos aos envolvidos sobre valores fundamentais para a construção das relações interpessoais na atenção médica, sendo o amor revelado como o valor-matriz fundante de uma ética com potência para fundamentar a ação política da boa clínica. Concluiu-se que a relação interpessoal que a medicina para o Brasil requer é uma relação interpersonas em diálogo com o contexto da pessoa cuidada; uma relação entre, com, especialmente no contexto da atenção básica, contexto macro das reflexões que aqui serão apresentadas. 


\section{KEY-WORDS}

- Interpersonal Relations.

- Community-Institutional Relations.

- Education, Medical.

- Primary Health Care.

- Brazilian Unified Health System.

\begin{abstract}
The Brazilian Unified Health System (SUS), a piece of national heritage achieved at the VIII National Health Conference, is recognized by the 1988 Federal Constitution. The same Constitution that approved the creation of the system, also required a democratic horizon for health training in Brazil to be developed through teaching, research and community outreach activities. That required horizon became feasible (and remains constitutionally valid) due to art. 207 of the Federal Constitution that determines that universities fulfill the principle of being inseparably linked to the three education modalities. This article analyzes the ethical, political and epistemological features of the interpersonal relations experienced within the Sérgio Arouca Project from the perspective of Medicine students from the University of Vale do Itajai (SC), Brazil. The Sérgio Arouca Project was designed in 2009, inspired by the Rondon Project. It has community outreach characteristics and its objective is to afford Medicine students the opportunity to be immersed in the social context of primary health care services in socially disadvantaged territories in the state of Santa Catarina. This research is a qualitative, exploratory, analytical social study. Combining teaching, community outreach and research, it was developed by seven academic students using focus group and field diary methods. The findings demonstrated that interpersonal relations developed in the context of the Project were pervaded by applied ethics, dialectic epistemology and responsive political action with oneself and with other members of the group. Thus, the Project was considered a respite, decelerating processes and valuing education outside the everyday epistemological, curricular structure and thereby presenting the opportunity to experience encounters and reflect on the fundamental values for building interpersonal relationships in medical care, where love is revealed as the underlying matrix-value of an ethics with the power to substantiate the political action of good clinical practice. It was concluded that the interpersonal relationship that Medicine requires for Brazil is an inter-people relationship in dialogue with the context of the cared person; a relationship, especially in primary care, with the macro context of the reflections that will be presented here.
\end{abstract}

Recebido em: 26/2/19

Aceito em: 30/3/19

\section{INTRODUÇÃO}

O Sistema Único de Saúde (SUS) é um patrimônio nacional, conquistado na VIII Conferência Nacional de Saúde ${ }^{1}$, em 1986. Reconhecido pela Constituição de 1988 como uma política social de caráter federativo, com comando único em cada esfera de governo, pautado na universalidade das ações e serviços públicos de saúde, na igualdade de acesso e atendimento integral, organizado por uma rede regionalizada e hierarquizada, em bases descentralizadas e participativas, o SUS exigiu, da mesma Constituição que o afirmou, um horizonte democrático para a formação em saúde no Brasil ${ }^{2}$.

O horizonte requerido fez-se possível - e está constitucionalmente vivo -, graças ao art. 207 da Constituição Federal ${ }^{3}$, que determina às universidades o cumprimento do princípio da indissociabilidade entre ensino, pesquisa e extensão, isto é, a necessidade de o estudante vivenciar, além do ensino, a produção científica e atividades extensionistas em interlocução com o mundo real.
No âmbito da formação médica para o Brasil, a Câmara de Educação Superior do Conselho Nacional de Educação instituiu as Diretrizes Curriculares Nacionais do Curso de Graduação em Medicina (DCNCGM) 4 em 2001, definindo as bases, condições e procedimentos necessários à formação de médicos para o País. Um de seus fundamentos é o perfil do médico a ser preparado para atuar em conformidade com as perspectivas políticas do SUS: "[...] formação generalista, humanista, crítica e reflexiva $[\ldots]^{\prime \prime}$.

A partir das disposições desta Resolução, as instituições de ensino superior (IES) em Medicina iniciaram um processo de revisão e remodelamento de suas estruturas curriculares, visando à garantia da construção acadêmica sustentada pelas três modalidades formativas. Atividades como iniciação científica, estágios supervisionados e projetos de extensão passaram a ser mais bem valorizadas por projetos pedagógicos ${ }^{6,7}$.

Em 2014, as DCNCGM foram atualizadas. Os atributos do perfil dos egressos foram mantidos e, no âmbito da qua- 
lidade da atenção à saúde, as diretrizes consideraram que o graduando deve desenvolver o "pensamento crítico, que conduz o seu fazer, nas melhores evidências científicas, na escuta ativa e singular de cada pessoa, família, grupos e comunidades nas políticas públicas, programas, ações estratégicas [...] vigentes $^{\prime \prime}$. Na esfera da pesquisa, a promoção do pensamento científico foi potencializada mediante o "favorecimento ao desenvolvimento científico e tecnológico voltado para a atenção das necessidades de saúde individuais e coletivas, por meio da disseminação das melhores práticas e do apoio à realização de pesquisas de interesse da sociedade" ${ }^{\prime \prime}$.

A partir de então, um dos espaços de maior capilaridade para o desenvolvimento de pesquisas e para a execução de atividades práticas na formação em Medicina tem sido o da atenção básica. A atenção básica é o espaço social do Sistema Único de Saúde (SUS) responsável pela resolução das necessidades humanas de base implicadas nos processos de saúde e de doença de pessoas e comunidades ${ }^{9}$. É a expressão brasileira da Atenção Primária à Saúde (APS), Primary Health Care, componente estratégico produzido nas relações de hegemonia da Organização Mundial da Saúde (OMS), entre 1948 e 1975, para orientar serviços nacionais de saúde ${ }^{10}$

Desde as primeiras iniciativas empreendidas na história da Saúde Pública até sua difusão pela OMS em 1978¹1, a APS tem sido objeto de estudos nacionais e internacionais, na medida em que pode ser interpretada por, pelo menos, quatro modos: a) como filosofia, com enfoque na equidade social, desenvolvimento e autonomia; b) como estratégia, na perspectiva de participação comunitária, colaboração intersetorial e reorientação do sistema de saúde; c) como nível de atenção, no sentido de apropriado, efetivo e alcançável; d) como programa, limitado a atividades essenciais ${ }^{12}$. Esses modos associados à estratégia da APS podem ser pensados e contextualizados, desde sua origem, por meio de características éticas, políticas e epistemológicas.

No Brasil, a APS foi impulsionada pelo processo de municipalização e criação do Programa Agentes Comunitários de Saúde e Programa Saúde da Família na década de 1990. Atualmente, configura-se na Política Nacional de Atenção Básica (PNAB), com base nas seguintes diretrizes: regionalização e hierarquização; territorialização e população adscrita; cuidado centrado na pessoa; resolutividade; longitudinalidade do cuidado; coordenação do cuidado; ordenamento da rede e participação comunitária ${ }^{13}$.

$\mathrm{Na}$ interseção entre o perfil do egresso (futuro médico), previsto nas novas diretrizes curriculares para os cursos de Medicina, e o reconhecimento constitucional da modalidade extensão foi criado o Projeto Sérgio Arouca (PSA), em 2009, por docentes do curso de graduação em Medicina da Universidade do Vale do Itajaí (Univali), Itajaí (SC). Este projeto foi inspirado na experiência consolidada do maior projeto brasileiro de extensão na área da saúde - o Projeto Rondon - com o objetivo de propiciar a formação acadêmica em municípios do interior do Estado de Santa Catarina com baixo Índice de Desenvolvimento Humano. É desenvolvido no período de férias acadêmicas, para possibilitar ao estudante a imersão no contexto social da atenção básica de territórios catarinenses socialmente desfavorecidos ${ }^{14}$.

Este artigo analisa características éticas, políticas e epistemológicas das relações interpessoais experimentadas em uma vivência do Projeto Sérgio Arouca, na perspectiva de acadêmicos do curso de Medicina da Univali. Por relações interpessoais compreendem-se aquelas capazes de superar a histórica relação médico-paciente (ativo-passivo), no sentido de concretizá-la como "uma prática médica de pessoa para pessoa e entre pessoas ${ }^{\prime 15}$ no contexto familiar, comunitário, cultural e social.

\section{PERCURSO METODOLÓGICO}

Trata-se de um estudo social de natureza qualitativa, de nível exploratório e caráter analítico, desenvolvido em conformidade com a Resolução MS/CNS 466/2012 e aprovado pelo Comitê de Ética da Universidade do Vale do Itajaí (SC) em 29 de novembro de 2017 (parecer número 2.380.172 e CAAE 78983617.1.0000.0120).

O ponto de partida de seu delineamento foi a divulgação do edital do Projeto Sérgio Arouca 2018-1 (PSA), lançado nos principais meios de comunicação do curso. Inicialmente, o edital do PSA 2018-1 previu 60 vagas; entretanto, durante o planejamento das ações, a comissão organizadora decidiu oferecer 80 vagas a alunos do curso de Medicina matriculados a partir do quinto período que já haviam cursado a disciplina Medicina da Família e Comunidade (MFC) ou a disciplina Atenção Básica. Os alunos interessados inscreveram-se espontaneamente dois meses antes da data estabelecida para o início do curso.

Desta maneira, compôs-se uma amostra intencional, cujo corpus empírico foi constituído por acadêmicos que manifestaram desejo de participação, cientes das características e abrangência do projeto oferecidas no edital.

No final do período de inscrição, havia 93 inscritos; após desistências, todos eles foram contemplados, sendo que, por fim, participaram do projeto 77 estudantes. Neste número total de alunos participantes ficaram representados oito períodos da graduação, do quinto ao décimo segundo período.

Para maior representatividade dos estudantes de Medicina, foi previsto, no desenho metodológico, sortear um aluno 
de cada período envolvido no PSA, compondo uma amostra de oito participantes (um representante de cada período, do quinto ao décimo segundo período).

Assim, foram respeitados os níveis de formação em que os estudantes se encontravam, na tentativa de trazer relatos que se acrescentassem ou complementassem ${ }^{16}$ (p. 197). No entanto, no momento imediatamente anterior à coleta de dados, houve uma desistência de participação; assim, a amostra final foi composta por sete acadêmicos de Medicina, representando alunos do quinto ao décimo segundo período, com exceção de representante do nono período.

A coleta de dados ocorreu em Urubici (SC), município da serra catarinense com uma população residente aproximada de 11 mil habitantes. Apesar de ser um destino turístico por conta das belezas naturais e da área montanhosa que registra as temperaturas mais baixas do País, o município possui um dos piores índices de desenvolvimento humano (IDH) do Estado de Santa Catarina (posição 254 entre 293 municípios). Segundo o Instituto Brasileiro de Geografia e Estatística, o salário médio mensal dos trabalhadores formais em 2016 era de 1,8 salários mínimos. A taxa de mortalidade infantil do município é de 7,19 óbitos por mil nascidos vivos ${ }^{17}$.

Especialmente as comunidades de baixa renda carecem de programas de promoção e atenção à saúde. Por essa razão, o município foi escolhido pela comissão organizadora como espaço para a execução do projeto, que inclui atividades ligadas à saúde da mulher, saúde do idoso, saúde da criança, saúde mental, doenças crônicas e dia da cidadania.

O período de permanência do projeto no município foi de seis dias, de 22 a 28 de janeiro de 2018. Durante esse período, foram realizadas consultas, atendimentos, visitas domiciliares e diversas atividades de educação em saúde, o que garantiu que os acadêmicos envolvidos na pesquisa tivessem tempo suficiente para se relacionar entre si - como colegas em atividades de planejamento e de execução das ações de atenção básica - e com membros da comunidade visitada.

As técnicas de coleta de dados utilizadas foram diário de campo e entrevista coletiva do tipo grupo focal (GF).

Os diários de campo foram produzidos durante os seis dias de participação no PSA para anotação de observações não verbais e de fatos percebidos como vinculados ao objeto de pesquisa. Posteriormente, os registros foram sistematizados e utilizados na discussão dos dados.

Inspirado em Krueger e Casey ${ }^{18}$, o GF foi desenvolvido no final da execução do projeto, lançando-se mão de um sistema de rodízio nas posições de moderadora e observadora. Logo no início do encontro, foi esclarecida a dinâmica do grupo, enfatizando-se a importância de interlocução e participação de todos para a construção coletiva de impressões sobre as relações interpessoais experimentadas durante a semana do PSA. Antes de cada fala, os estudantes se identificavam pelo número que lhes fora atribuído aleatoriamente pela entrega de crachás numerados de 1 a 7 . Assim, o anonimato foi garantido por meio da utilização dos números que os identificariam na transcrição dos dados. O ambiente privado - numa das salas que estavam sendo utilizadas para alojamento dos estudantes - foi organizado formando um círculo para que todos os participantes estivessem dentro de um campo de visão comum, valorizando a interação de todos com base nas questões previamente semiestruturadas. Os dados coletados foram registrados por dois gravadores de voz, estrategicamente posicionados na sala, compondo o material utilizado para posterior transcrição literal. O GF teve duração de 1 hora e 57 minutos.

Após a transcrição, o material foi submetido a uma exploração inicial, com vistas à organização. Frases incompletas que não apresentavam sentido e vícios de expressão foram excluídos. A análise preliminar se deu por meio de leitura intensa e flutuante, de modo a permitir a impregnação do conteúdo. Em seguida, definiram-se as unidades de registro e de contexto e procedeu-se à codificação das unidades de registro. Bagagem, vivências, experiências e referencial teórico participaram do processo de codificação, realizado por meio de uma adaptação do método temático tradicional, que toma por base não a contagem de frequência de unidades de registro, mas a presença de unidade com significado relevante para o objeto analítico ${ }^{16(p .192)}$.

Em sequência, procedeu-se àquela que, em última análise, corresponde ao produto que representa o texto (material bruto) coletado no contexto do PSA: a fase de categorização. Para isto, as pesquisadoras se distanciaram da sistematização e retomaram o material transcrito, buscando garimpar eventuais unidades de significação a respeito de determinada questão em resposta a outros questionamentos, uma vez que o tecnicismo da codificação pode ocultar eventuais unidades de significação. O material foi atentamente explorado, de modo transversal, para realizar esta verificação.

Feito isto, realizou-se a produção de significados e interpretação. Três vértices compuseram esta fase, não de modo linear, mas por meio de um contínuo atravessamento dialógico: o instrumental, o teórico e o reflexivo. Ou seja, categorizou-se o material com base no exercício compreensivo sobre os códigos agrupados, produzido na interlocução entre a dimensão instrumental, a subjetividade e a bagagem teórico-prática. Com base nas subcategorias deflagradas "PSA: espaço-tempo"; "encontros"; e "amor: valor-matriz das relações interpessoais necessárias à boa clínica", delineou-se a categoria do estudo: "trégua". 


\section{RESULTADOS E DISCUSSÃO}

Os resultados são expostos avançando-se de uma descrição inicial sobre características éticas, políticas e epistemológicas com a intenção de, inicialmente, situar a perspectiva assumida pelas autoras para a análise do objeto - relações interpessoais -, para depois apresentar o sentido da categoria "trégua", seguido do diálogo entre unidades de registro e referenciais teóricos e estilo de pensamento das autoras, visando à estruturação do caminho analítico.

Sobre as características epistemológicas, pode-se dizer que são as oriundas da corrente de pensamento que, no momento histórico da vivência, ancora o pensar e o fazer medicina de acadêmicos. Por exemplo, a relação que o estudante faz entre o tempo da formação prática curricular (tradicional) e a oportunidade-tempo do PSA revela a dimensão epistemológica da categoria tempo: na fase de formação, o estudante constrói para si um conhecimento de mundo; no caso, um entendimento sobre o tempo com potência formadora para definir o mundo-tempo, aquele que fundamentará suas relações futuras na atenção médica.

[...] quando falas da construção de uma boa relação interpessoal, é sempre bom lembrar que qualquer relação demanda tempo (suj. 3)

[...] se eles querem que eu atenda uma pessoa em cinco minutos, em dez, em quinze, vão ser os melhores quinze minutos que ela vai ter pra falar do problema dela. (suj. 6)

As características políticas das relações interpessoais convergem para o potencial transformador do Projeto Sérgio Arouca. É uma oportunidade didática e pedagógica para relacionar conteúdos teóricos, pertinentes ao SUS, com realidades sociais muito distintas daquelas do município sede da universidade e seu entorno. Elas expressam as particularidades de eventuais conflitos entre o modelo de formação universitária, orientado por projeto pedagógico e corpo docente, e o modelo que se realiza na liberdade da formação extramuros, em cada situação concreta experimentada por acadêmicos no locus de vida de usuários da atenção básica.

[...] o projeto dá a oportunidade de, fora do consultório, a gente conseguir continuar conversando com o paciente nas dinâmicas... com outros olhos, assim, ver a relação dele com a comunidade, com os familiares dele também. (suj. 2)

Por características éticas das relações interpessoais compreendem-se particularidades da ética aplicada em sua dimensão filosófica, ou seja, particularidades do exercício reflexivo que precede a escolha/tomada de decisão sobre a realidade apresentada pela pessoa cuidada, com vistas à produção de bem, em relação, para cuidado e cuidador. Este exercício reflexivo é conduzido pelo sistema de valores coletivos e individuais à disposição, materializado pela escolha mais racional, razoável e cautelosa possível, e finalizado na responsabilização ${ }^{19,20}$. A uma dimensão ética da prática médica, exercida horizontalmente, correspondem atitudes precedidas de reflexão:

[...] e crítico também inclui, não sei, ser um ser humano, sabe? Tipo, crítico na política... em tantos aspectos, pra mim são muito abrangentes esses termos, eu acho que reflexivos e críticos deveriam ser para todas as profissões, para todas as pessoas, assim a gente conseguiria fazer um país melhor, sabe? Não é uma coisa só para os médicos... (suj. 3)

O Projeto Sérgio Arouca - como projeto extensionista entra de certa forma como "trégua" para os estudantes de Medicina no sentido de parar a correria, de poder desacelerar os tempos, de olhar para si, para o outro, para a medicina:

A gente usa muito aqui a criatividade e é uma coisa que é pouco utilizada no dia a dia da medicina. A gente é barrado o tempo todo pelos professores, pela gestão, pela gente mesmo, que tem medo de fazer alguma coisa diferente e ser julgado. E aqui eu vi que a gente pode ser criativo. (suj. 3)

Trégua como sinônimo de suspensão, interrupção, descanso, repouso, pausa. Um armistício, um acordo que suspende temporariamente as hostilidades entre as práticas (e valores e conhecimentos) vivenciadas nas atividades curriculares tradicionais e um espaço-tempo aberto a novos encontros e às reflexões que apareceram no percurso da pesquisa.

Se a vida, desde os gregos, parece ser contínua luta ( $\alpha \gamma \omega \dot{v} \alpha \varsigma$ - agónas) em torno de objetivos obscurecidos pelo barulho de fundo de uma sociedade desigual, injusta e apressada, uma

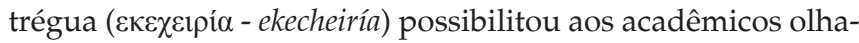
rem para si, para dentro e para fora, nas três dimensões estudadas, e refletir sobre as oportunidades que a medicina potencialmente apresenta, seus valores, sobre amar e ser amado, sobre ética e clínica e as políticas de atenção básica ${ }^{21}$.

Para os gregos, ekecheiría - que significa aperto de mãos - representa um momento ritual em que todos os envolvidos em lutas ou guerras se permitem parar, recolher as armas e se dedicar aos jogos em paz ${ }^{21}$. Novos espaços, outro tempo, de despertar outros valores, outros comportamentos, instalar outra política. 
Eu fico tão preocupada em esquecer de anotar alguma coisa, que eu esqueço de perguntar, que eu esqueço de saber se é importante pra ela ou não. (suj. 6)

Contextualizando a dialética entre ensino e extensão, no âmbito das relações interpessoais necessárias à boa clínica, observou-se que, da mesma forma que acadêmicos apontaram o PSA como uma oportunidade de tempo pensada fora da estrutura epistêmica curricular do dia a dia da formação, eles também fizeram referência ao PSA como oportunidade-espaço. Oportunidade, enquanto dimensão política para atuar em campo de forma não constrangida, sem ceder às pressões academicistas de produtividade técnica ou de limitações tempo-espaciais tradicionais, impostas. Oportunidade para atuar em um campo de práxis que permite ao futuro médico intuir suas potencialidades como ser que se relaciona, liberto para criar, utilizando sua singularidade em favor da construção de um espaço único onde pode estabelecer sua própria relação de médico com aquele que a ele se apresenta em busca de atenção e cuidado, conforme o depoimento a seguir:

Eu sinto que me aproxima demais, porque tem... Uma das coisas que eu sinto nas práticas no ambulatório e hospital é a falta de tempo pra poder conversar melhor com os pacientes, estabelecer um vinculo e entender melhor o que se passa com cada pessoa. E eu acho que aqui a gente tem essa oportunidade de criar laços. Mesmo que a gente vá embora domingo, a gente consegue estabelecer uma conexão que é bem interessante. (suj. 7)

Quando questionados sobre a base das relações interpessoais no exercício da medicina, acadêmicos expuseram um conjunto expressivo de unidades de registro, com características de ordem prática que puderam ser subsumidas em um valor maior: amor. O exercício de reflexividade dirigida sobre esta unidade de significância, em interlocução com a bagagem prático-teórica e referencial teórico, resultou na compreensão do amor como valor-matriz.

Como disse um dos estudantes:

Eu queria falar, não sei se é adequado para a situação, mas eu acho que o valor humano mais imprescindivel para isso tudo é o amor. É uma palavra forte, que tem diversos sentidos, significados... mas eu acho que ela pode basear muito as coisas. [...] Se a gente tiver amor no que a gente faz e amor pra demonstrar para o outro, significa que a gente vai querer somente o bem dessa pessoa e o nosso bem também. Tudo que vem depois disso... empatia, respeito, ética, inúmeros outros valores, todos advêm do amor, que eu acho que é necessário ter para uma boa clínica. (suj.7)

Na medida em que há receio de associar amor com relações interpessoais no exercício da medicina, o estudante parece demonstrar amarras pragmáticas, como se o bem produzido na clínica médica se esgotasse no valor prático de um desfecho imediato, em que não concorrem reflexão, crítica a argumentos, intersubjetividade e contexto do enredo.

Ao fazer referência à necessidade de se ter amor "no que a gente faz e pra demonstrar para o outro" com vistas a argumentá-lo como a célula para uma boa clínica, o acadêmico apresenta como produto dessa necessidade um objeto ideal da tradição filosófica: o bem, "querer o bem" do outro e de si. Se preenchida de amor, "a gente vai querer somente o bem". Essa hermenêutica remonta a Aristóteles, que definiu o termo bem, em Ética a Nicômaco, como realidade, fim último, exatamente por ser desejado, isto é, ser desejado é que define o bem. Ou seja, "o bem não é desejado por ser perfeição e realidade, mas é perfeição e realidade por ser desejado"22(p. 5), sendo o desejo expresso pelo amor.

No âmbito do senso comum, os significados apresentados pelo termo amor são variados, desiguais e contrastantes; igualmente variados, desiguais e contrastantes são os significados que se apresentam na tradição filosófica. Entre os usos mais correntes na linguagem do senso comum com significados próprios e irredutíveis, procedentes e pertinentes à discussão sobre o objeto deste artigo, vale citar o amor designando "uma vasta gama de relações interpessoais entre [...] cidadãos [em direção] à comunidade ou a entes coletivos [...] um tipo específico de relação humana caracterizado pela [...] concórdia dos indivíduos que dele participam"23(p.39). O caráter da concórdia, neste contexto, não pode ser determinado de modo absoluto, uma vez que o amor entre cidadãos que se consideram avizinhados possui diferentes bases culturais e sociais e é afetado por diferentes níveis de "intimidade, familiaridade e emotivi-

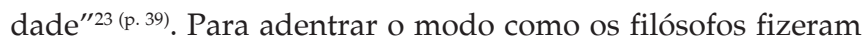
uso deste termo, é preciso atentar para esta diversidade.

$\mathrm{Na}$ medida em que o amor foi pensado e refletido pelos acadêmicos em sua dimensão filosófica, o esforço da análise aqui empreendida estará dirigido ao tratamento do termo enquanto conceito filosófico, o que pode ser imaginado como uma abóbada ou um guarda-chuva (uma imagem de pensamento) onde os demais valores podem ser acomodados.

Amor entre os gregos era visto como algo a ser compartilhado por poucos, apenas para gregos: não para os estrangeiros ou escravos. Sócrates, em O Banquete (2013), de Platão ${ }^{24}$, senta-se com seus poucos amigos e discute o conceito 
de amor de diversas formas, como, por exemplo, como eros (amor sensual) e como philia (interação de amigos em busca da eudaimonia como sumo bem). Essa obra representa o primeiro tratamento filosófico dado ao amor. Entre as diferentes formas apresentadas por Platão, está a designação de amor como necessidade $^{24}$, supostamente uma necessidade grega, podendo ser extrapolada como necessidade humana.

Na ética judaica, ainda, o amor de Deus não era destinado a todos. A ira divina poderia recair sobre os infiéis, sendo somente a partir das reflexões de Agostinho (354-430) a respeito da Verdade revelada pela bíblia que acontece uma grande revolução conceitual em relação ao amor na história da filosofia ${ }^{25}$ :

\begin{abstract}
A revolução moral feita por Jesus de Nazaré na ética judaica tradicional baseada no Decálogo de Moisés consiste basicamente na introdução do amor universal como base do relacionamento moral humano: trata-se de amar a todos, não somente o próximo, incluindo os inimigos. [...] Eis, então, a contribuição de Jesus para a Ética: o amor a si, ao próximo e $a_{\text {Deus. }}{ }^{25(\mathrm{p} .201-202)}$
\end{abstract}

A partir de então, o amor (ágape) passa a ser considerado, na ética cristã, como base para todas as virtudes. Para Agostinho, a virtude cardeal e, mais adiante, com a leitura aristotélica de Tomás de Aquino (1225-1274), o amor passa a ser compreendido como doação ou caridade (caritas) ${ }^{25}$ (p. 228-229).

Na modernidade, Immanuel Kant (1724-1804) relaciona amor ao sentimento moral de dever, distinguindo caridade prática, enquanto deveres do amor (amor benevolentiae), de caridade estética, quando o sentimento de amor está ligado à representação da existência de um objeto (amor complacentiae) ${ }^{26}$.

$\mathrm{O}$ dever moral, para Kant, se liga à máxima (enquanto imperativo categórico: algo que possa ser universalizado a todos) do querer bem (dimensão ética) com a consequência moral de fazer o bem (como prática: dimensão ético-política). Portanto, o amor como sentimento de ânimo moral é teorizado na lógica deontológica kantiana como não apenas motivando o agir, mas como sendo uma característica humana, nomeada de vontade boa que permite a todos compreender o dever moral como imperativo categórico ${ }^{26}$.

Assim, observa-se que, embora o enredo da história da filosofia ocidental não seja linear, o conceito de amor passa dos gregos como eros ou philia: termos que trazem em si a dependência de certas características no outro para que haja amor; do amor judaico exclusivo e excludente: dependente de determinações divinas; para os preceitos de amor do Novo Testamento: todos iguais perante o merecimento de amor (ágape) com as reflexões de Agostinho; de caridade e doação a partir de Tomás de Aquino (caritas); chegando a um caráter de dever moral em Kant (amor benevolentiae).

Numa aproximação da história da filosofia ocidental recente, há um filósofo que, na solidão do cárcere, sublimou sua história pessoal, marcada por isolamento e sofrimentos físicos e morais, e deu provas de amor à sua sociedade, externadas pelo sentido de sua pedagogia: Antonio Gramsci. Em seu vasto legado humanístico, encontra-se a organização de escolas para grupos de presos comuns e políticos, no confinamento em Ustica (1926-1927) e depois em um período do cárcere (1927-1932) e seu estudo teórico sobre problemas educativos, também desenvolvido no cárcere (1930-1932). O produto desse estudo foi a síntese de uma escola unitária de cultura, uma escola de base, correspondendo ao ensino fundamental e médio brasileiro, que formasse a um só tempo produtores (formação técnica) e intelectuais (formação humanística): uma escola integral, ativa e livre de disciplinas, pautada em certo "dogmatismo dinâmico". Ao final da pré-adolescência (15-17 anos), a escola de base seria "não somente ativa, mas criativa, com ilimitada autodisciplina intelectual, autonomia moral e consciência social homogênea". Em seguida, o jovem estaria pronto, histórica e politicamente, para, a partir de então, fazer escolhas profissionais. Gramsci foi, portanto, um filósofo que amou porque "existiu em ato" 27.

Essa diversidade de modos de conceber o amor, em distintos contextos e momentos históricos, dialoga com a percepção de acadêmicos na medida em que se torna impossível a compreensão de si, do outro, das relações de alteridade e do mundo sem apropriação do amor como valor-matriz, na dimensão ética da existência:

[...] existem várias formas de amor e vários jeitos de se abordar o amor. [...] às vezes, a gente tem que se despir de algumas coisas pra entender que o amor é muito mais que isso. Que não é só querer o bem do paciente acima de tudo e da vontade dele. Que amor também é entender a condição dele e o que ele quer pra ele. Não adianta o meu amor querer levar ele a um lugar que ele não quer ir. Então, acho que na faculdade a gente desenvolve o que a gente já tem, mas a gente aprende a ver outras formas... não são outras formas, mas assim, outras faces... encontrar o amor em outras atitudes, sabe? Pra conseguir levar isso no dia a dia. (suj. 6)

Com base em depoimentos de acadêmicos, é possível inferir que o amor, enquanto conceito filosófico, se não resolve a relação de um com outros - isto é, se não esclarece exatamente o conceito de outro ou traz uma fórmula rígida de como se 
relacionar com outros -, parece ser o valor-matriz fundante de uma ética com potência para justificar a ação política da boa clínica; de uma ética com potência para construir uma relação humanista, reflexiva e crítica de futuros médicos generalistas ocupados com as reais necessidades de pessoas; pessoas estas que dependem de condições materiais e emocionais de existência e que são proprietárias de vontades próprias: “[...] amor também é entender a condição dele e o que ele quer pra ele" (suj. 6). Este valor-matriz parece dar conta de abarcar as características elencadas pelos acadêmicos de Medicina como necessárias à boa prática dos cuidados em saúde:

- Ter liberdade para definir estratégias de atendimento (ou seja, ter liberdade para deliberar, por exemplo, em conformidade com seu sistema de valores);

- "Ter o tempo" necessário para cada consulta ou intervenção;

- Ter espaço e condições para dimensionar as necessidades de saúde de usuários, famílias e comunidades;

- Desenvolver a sensibilidade para apropriar-se de uma linguagem clara e acessível, que venha ao encontro das singularidades do senso comum, das pessoas, em suas diferenças culturais e sociais;

- Assumir o compromisso com deliberações compartilhadas.

Na visão de $\operatorname{Rios}^{28}$, a boa prática médica exige combinar a prática de educação, cuidado, prevenção e promoção da saúde das pessoas e comunidades; estar consciente dos condicionantes sociais envolvidos na atenção básica; refletir de forma a poder se tornar agente de transformação; conhecer as singularidades e diferenças e respeitar a diversidade humana; ter sempre presente o compromisso ético da profissão, identificando valores que priorizem a vida e o alívio do sofrimento dos pacientes; trabalhar em equipe - tudo isso perpassado pelo que a autora chamou de zelo, teorizado neste artigo como amor/valor-matriz.

Como mostrado na Figura 1, a área externa do quadrado maior simboliza o PSA como campo onde ocorreram encontros. Cada pequeno quadrado seria um dos sujeitos envolvidos na pesquisa: acadêmicos e moderadora-observadora; e cada um dos pequenos círculos representa as características listadas para a boa prática dos cuidados em saúde, todas contidas pelo valor-matriz.

\section{ALGUMAS CONSIDERAÇÕES}

Foi possível perceber, na relação com os dados, que o Projeto Sérgio Arouca (PSA) se revela uma oportunidade de aprendizagem, pois, ao mesmo tempo em que permite refletir sobre os
Figura 1

Representação do PSA como "trégua", um espaço-

tempo de encontros. Em azul, os sujeitos da pesquisa/

pesquisadoras. Nos círculos, as dimensões ético-

políticas: coloridos periféricos - características

necessárias à boa prática dos cuidados em saúde; todas

contidas no rosa centralizado - amor (valor-matriz)

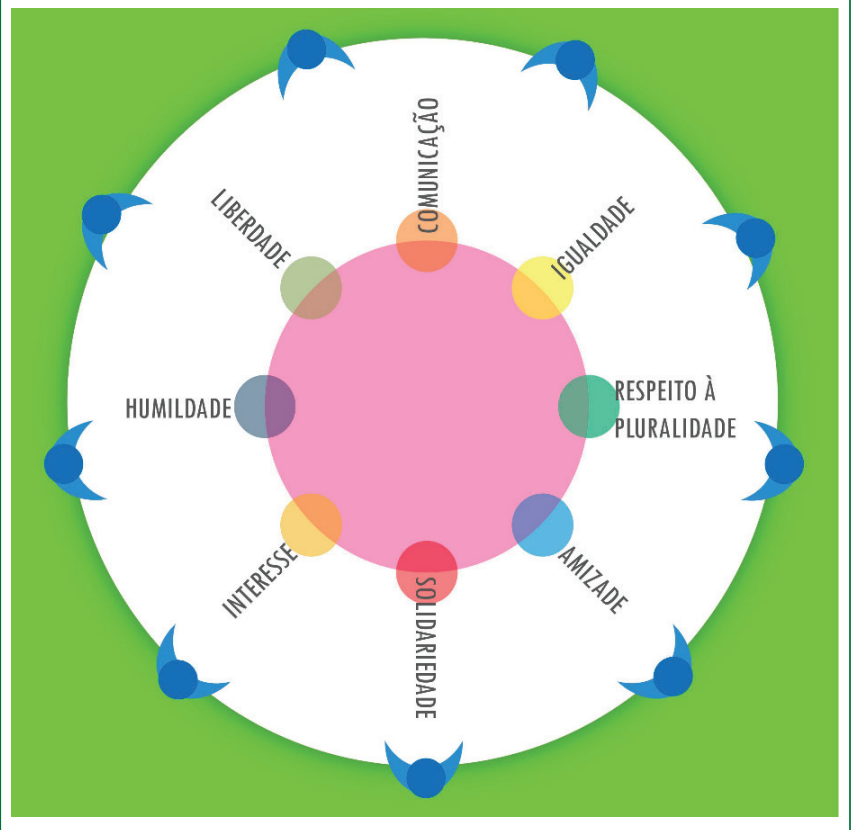

Fonte: Elaborado pelas autoras.

sistemas de valores para compor uma ética, oferece uma visão do campo de aplicação, possibilitando aos estudantes vislumbrar uma prática comprometida com as reais necessidades das pessoas que atenderão. Compõe, assim, uma experiência de reflexão para uma atuação que enxerga os futuros "pacientes" em sua singularidade existencial, afetiva, pluralidade, inserção social, diversidade cultural e fragilidades sociais.

Ressalta-se também uma epistemologia dialética que concebeu a construção do conhecimento no PSA como espaço-tempo diferenciado - uma trégua -, isto é, uma pausa da vida curricular de estudantes de Medicina e uma oportunidade diferente para as comunidades vivenciarem essa forma diferente de um fazer em saúde. Esta trégua possibilitou encontros que permitiram a reflexão sobre valores fundamentais para a construção da relação interpessoal, tão necessária no dia a dia dos cuidados da atenção básica, chegando ao amor como valor-matriz de uma ética da relação interpessoal entre profissionais comprometidos com a dimensão política dos cuidados médicos dirigidos àqueles que os requerem. 
Outra consideração refere-se ao caráter do estudo: em se tratando de uma pesquisa qualitativa, as considerações geradas pela análise dos dados não são finais, mas provisórias, transitórias, inacabadas, porque concebidas na dialética dos processos humanos. Neste sentido, a rede de remissões tão necessária à pesquisa qualitativa deixa sempre portas abertas para outros olhares, a partir de diferentes referenciais teóricos que podem incrementar o nível de compreensão da realidade tanto dos profissionais envolvidos nos cuidados de saúde quanto das comunidades envolvidas nos projetos de extensão.

$\mathrm{Na}$ mesma medida, há que se considerar que o estudo apresenta o limite de ter enfocado apenas um sujeito da produção de cuidados em Medicina: o acadêmico/futuro médico para a atenção básica do SUS. Estudos futuros que deem voz a usuários e demais trabalhadores da atenção básica são bem-vindos e oportunos.

Por fim, com base na relação com os dados, as autoras compreenderam que a relação interpessoal que a medicina para o Brasil requer é uma relação interpersonas, em diálogo com o contexto da pessoa cuidada; uma relação entre, com, especialmente no contexto da atenção básica, contexto macro das reflexões aqui apresentadas. Nesta linha compreensiva, fazem um chamado para a importância deste tipo de relação na construção de egressos em Medicina reflexivos e críticos da realidade.

Consoante uma fórmula poética, vinda de um jovem - assim como todos os envolvidos neste estudo -, os valores éticos expressos pelos estudantes de Medicina neste estudo são resumidos na frase: eu é um outro - je est um autre ${ }^{29}$.

\section{REFERÊNCIAS}

1. Brasil. Ministério da Saúde. Oitava Conferência Nacional de Saúde: Relatório final. Brasília, 21 mar. 1986.

2. Brasil. Presidência da República. Casa Civil. Constituição da República Federativa do Brasil. Brasília, 5 out.1988.

3. Brasil. Presidência da República. Casa Civil. Constituição da República Federativa do Brasil. Capítulo III, da Educação, da Cultura e do Desporto. Seção I, da Educação. Art. 207. Brasília, 5 out. 1988.

4. Brasil. Ministério da Educação. Conselho Nacional de Educação. Câmara de Educação Superior. Resolução CNE/ CES n⿳⺈ 4 de 7 de novembro de 2001. Institui diretrizes curriculares nacionais do curso de graduação em Medicina. Diário Oficial da União. Brasília, 9 nov.2001.

5. Brasil. Ministério da Educação. Conselho Nacional de Educação. Câmara de Educação Superior. Resolução CNE/CES nº 4 de 7 de novembro de 2001. Diário Oficial da União. Brasília, 9 nov.2001. Artigo nº 3.
6. Franco CAGS, Cubas MR, Franco RS. Currículo de medicina e as competências propostas pelas diretrizes curriculares. RevBrasEducMed 2014;38(2):221-230.

7. Resende JC, Alves RBS, Coutinho MS, Bragagnoli G, Araújo CRF. Importância da Iniciação Científica e Projetos de Extensão para Graduação em Medicina, RevBrasCiênc Saúde 2013;17(1):11-18.

8. Brasil. Ministério da Educação. Conselho Nacional de Educação. Câmara de Educação Superior. Resolução CNE/ CES n³ de 20 de junho de 2014. Institui Diretrizes Curriculares Nacionais do Curso de Graduação em Medicina e dá outras providências. Diário Oficial da União. Brasília, 6 de jun.2014.

9. Liz RG, Lima RCGS. Percepções de usuários sobre o impacto social do projeto de cooperação do Programa Mais Médicos: um estudo de caso. Interface (Botucatu) 2017;21(1):1281-1290.

10. Lima RCGS. Atenção Primária à Saúde como um produto da hegemonia: análise das Assembleias Mundiais de Saúde da OMS, 1948-1978. Florianópolis; 2013. Doutorado [Tese] - Universidade Federal de Santa Catarina.

11. Rovere M. Atención Primaria de la Salud en Debate. Saúde debate 2012;36(94):327-342.

12. Barten F. Comentario sobre investigación en sistemas de salud, atención primaria de salud y participación para la transformación social. Saúde debate 2012;36(94):348-351.

13. Brasil. Ministério da Saúde. Gabinete do Ministro. Portaria $\mathrm{n}^{\mathrm{0}}$ 2436, de 21 de setembro de 2017. Aprova a Política Nacional de Atenção Básica, estabelecendo a revisão de diretrizes para a organização da Atenção Básica, no âmbito do Sistema Único de Saúde (SUS). Diário Oficial da União. Brasília, 22 set. 2017; Seção 1,p.68.

14. Maeyama MA, Cutolo RA, Chaves MV, Barni RS. Projeto Sérgio Arouca: Relato de Experiência. Rev Bras Educ Med 2016;40(1):118-127.

15. Lima RCGS, Verdi MIM. Capitalismo e Ontologia da Bioética: o processo de trabalho de médicos de família na Itália. Trab. educ. saúde 2015;13(2):323-341.

16. Minayo MCS. O desafio do conhecimento. Pesquisa qualitativa em saúde. São Paulo- Rio de Janeiro: HUCITEC-ABRASCO,2014.

17. Brasil. Instituto Brasileiro de Geografia e Estatística. 2017 [capturado 28 out. 2018]. Disponível em: https:/ / cidades. ibge.gov.br.

18. Krueger RA, Casey MA. Focus groups: a practical guide for applied research. London: SAGE,2009.

19. Berlinguer G. Questões de Vida: Ética, Ciência, Saúde. Salvador-São Paulo-Londrina: APCE-HUCITEC-CEBES,1993. 
20. Cortina A. O fazer ético: guia para a educação moral. São Paulo: Moderna,2003.

21. Schilling V. Olimpíadas: a trégua olímpica. [capturado 06 out. 2018]. Disponível em: http://educaterra.terra.com. br/voltaire/cultura/2004/06/17/002.htm.

22. Aristóteles. Ética a Nicômaco. São Paulo: Edipro,2014.

23. Abbagnano N. Dicionário de Filosofia. São Paulo: Martins Fontes,2007.

24. Platão. O Banquete. São Paulo: Edipro,2013.

25. Dall'Agnol D.Ética. Florianópolis: Filosofia/EAD/ UFSC,2008. Cap. 4: A Ética na Filosofia Medieval.

26. Schmidt EE, Schonecker D. O amor em Kant e na filosofia analítica. Con-Textos Kantianos 2017;(5):75-93.

27. Manacorda MA. Antonio Gramsci. L'alternativa pedagogica. Roma: Editori Riuniti, 2012.

28. Rios IC. Humanidades e medicina: razão e sensibilidade na formação médica. Ciênc. saúdecoletiva 2010;15(1):17251732.

29. Rimbaud A. Correspondência. Rio de Janeiro: Topbooks, 2009.

\section{CONTRIBUIÇÃO DOS AUTORES}

Júlia de Sá Liston contribuiu para a concepção, planejamento, análise e interpretação, e participou da aprovação da versão final do manuscrito.

Mariana Andréa de Moura Henicka contribuiu para a concepção, planejamento, análise e interpretação, e participou da aprovação da versão final do manuscrito.

Rita de Cássia Gabrielli Souza Lima contribuiu para a concepção, planejamento e interpretação, fez a revisão crítica do conteúdo e participou da aprovação da versão final do manuscrito.

\section{CONFLITO DE INTERESSES}

Não há conflito de interesses.

\section{ENDEREÇO PARA CORRESPONDÊNCIA}

Rita de Cássia Gabrielli Souza Lima.

UNIVALI. Rua Uruguai, 458 - Centro - Itajaí / SC

CEP 88302-202 - Bloco F6 - PMSGT. Sala 312 